\title{
BSC CURRICULA MEASUREMENT AND CONTROL ENGINEERING AT FACULTY OF TECHNICAL SCIENCES, UNIVERSITY OF NOVI SAD
}

\author{
Zoran Mitrović, \\ Platon Sovilj, \\ Bojan Vujičić, \\ Đorđe Novaković, \\ Marjan Urekar
}

Faculty of Technical Sciences, University of Novi Sad, Novi Sad, Serbia

\begin{abstract}
:
In ELEMEND project, BSc Curricula Measurement and Control Engineering at Faculty of Technical Sciences, University of Novi Sad, is one of the programmes which should be transformed and modernized in order to achieve the ELEMEND project goals. This paper presents the review of this studying programme, from perspective of programme structure, programme objectives, programme goals, graduate competencies and curriculum.
\end{abstract}

Keywords:

technical sciences, education, measurement, control, engineering.

\section{INTRODUCTION}

Faculty of Technical Sciences originates from the Faculty of Mechanical Engineering which was established by the Decree of the National Assembly of People's Republic of Serbia on 18th May 1960 as a Faculty of Mechanical Engineering in Novi Sad and it was a constituent part of the University of Belgrade. After the founding of the University of Novi Sad on 28th June 1960, the Faculty along with six previously established faculties in Vojvodina was regarded as a part of the University of Novi Sad.

In the first period of its development the Faculty provided educational activities for three different profiles of mechanical engineering. In 1971 electrical and civil engineering studies were founded. Establishment of the Department of Electrical Engineering as well as the Department of Civil Engineering brought about the change of its name into the Faculty of Technical Sciences on 22nd April 1974. In 1979/80 academic year started the studies in the area of traffic engineering, and in 1996/97 the first generation of students of architectural engineering was enrolled.

In academic year 1999/2000 several different studies for the new professional profile were introduced: Industrial Engineering and Engineering Management (the first generation of students of Industrial Engineering was enrolled in 1969, but within the Department of Mechanical Engineering), Graphic Engineering and Design, and Environmental Engineering. Study programme for Postal Services and Telecommunications were introduced at the Department for Traffic Engineering in $1999 / 2000$. 
Interdisciplinary studies of Mechatronics were established in 2002/03 academic year. In 2006/07 academic year the first generation of students of specialist academic studies was enrolled at the Faculty (according to the Law on Higher Education) and the studies of Geodesy and Geomatics engineering were introduced into the educational activities of the Faculty in 2007/08 academic year.

Furthermore, in 2009/2010 the studies of Safety at Work were established at the Department of Environmental Engineering as well as the undergraduate professional programme at the Department of Power Engineering - Renewable Energy Sources. In 2011/2012 academic year the following studies were established: Risk and Fire Protection Management, Animation in Engineering as well as undergraduate professional studies Software and Information Technology at the Faculty Department in Inđija; the same study programme was also introduced at the Faculty Department in Loznica in 2012/2013 academic year.

In 2013/2014 academic year the following study programmes will be established: Biomedical Engineering, Measurement and Control, Clean Energy Technologies, Stage Architecture, Engineering and Design, Electric Power Software Engineering, Software Engineering and Information Technology in Novi Sad as well as at the Faculty Department in Loznica and undergraduate professional studies within the study programme of Electronics and Telecommunication.

Master studies are organized at all study programmes after finishing undergraduate academic studies as well as at study programmes: Mathematics in Engineering; Energy Management; Logistic Engineering, Digital Technology, Design and Production of Architecture and Urban Planning, Industrial Engineering - Advanced Engineering Technology, Industrial Engineering - Development and Product Lifecycle Management, Planning and Management of Regional Development as well as Treatment and Water Protection (TEMPUS programme) which rounds off the educational activities of the Faculty.

Faculty of Technical Sciences offers a very prominent educational profile for prospective engineers, which ranks it among the most developed institutions in the field of technology in our country.

The study programme Measurement and Control Engineering has been created on the basis of modern scientific knowledge in the field of Electrical and Computer Engineering, modeled after similar study programmes at the leading universities in the world and in accordance with the Bologna recommendations and technology strategy development of AP Vojvodina and Serbia. Lectures within the undergraduate academic studies last 4 years and a graduate thesis is planned for the eighth semester. Students who successfully complete this study programme obtain a diploma in Electrical and Computer Engineering with the title of the study programme Measurement and Control Engineering, as well as information on particular competences that the students obtain during their studies.

The current state and, especially, trends in the development of electrical and computer engineering, especially in the field of measurement and control, form the basis for defining the structure and content of the study programme. For that reason a number of subjects at the lower years of study is defined in such a way to provide the necessary general and theoretical knowledge, as well as basic skills that lead the student to practical application of gained knowledge. Good balance between knowledge and skills at lower years provides good base for subjects at higher years, which are devoted primarily to specialized courses which are aimed at providing professional and applied knowledge in the narrow fields of interest.

Acquired knowledge and skills enable graduate students to successfully answer to the demands of the market and knowledge-based economy in the field of modern electrical and computer engineering. Particular knowledge and skills in fields of measurement and control engineering provide students after completing the programme to easily adapt to the industrial process in the field of measurement and control without additional courses in the company. At the same time, graduate students from this programme have good basic knowledge for higher levels of education on study programmes that follow this or similar programmes.

Lectures in professionally applied and scientificprofessional subjects are carried out by teachers from the Department of the Power, Electronics and Telecommunications Engineering, which is responsible for the study programme, and Department of Computing and Control Engineering at the Faculty of Technical Sciences in Novi Sad.

Lectures in theoretical-methodological and academic-general educational subjects are carried out by teachers from other departments of the Faculty of Technical Sciences. The practical part of the lectures is carried out in modern and well equipped laboratories in which students are trained to solve practical engineering problems. 

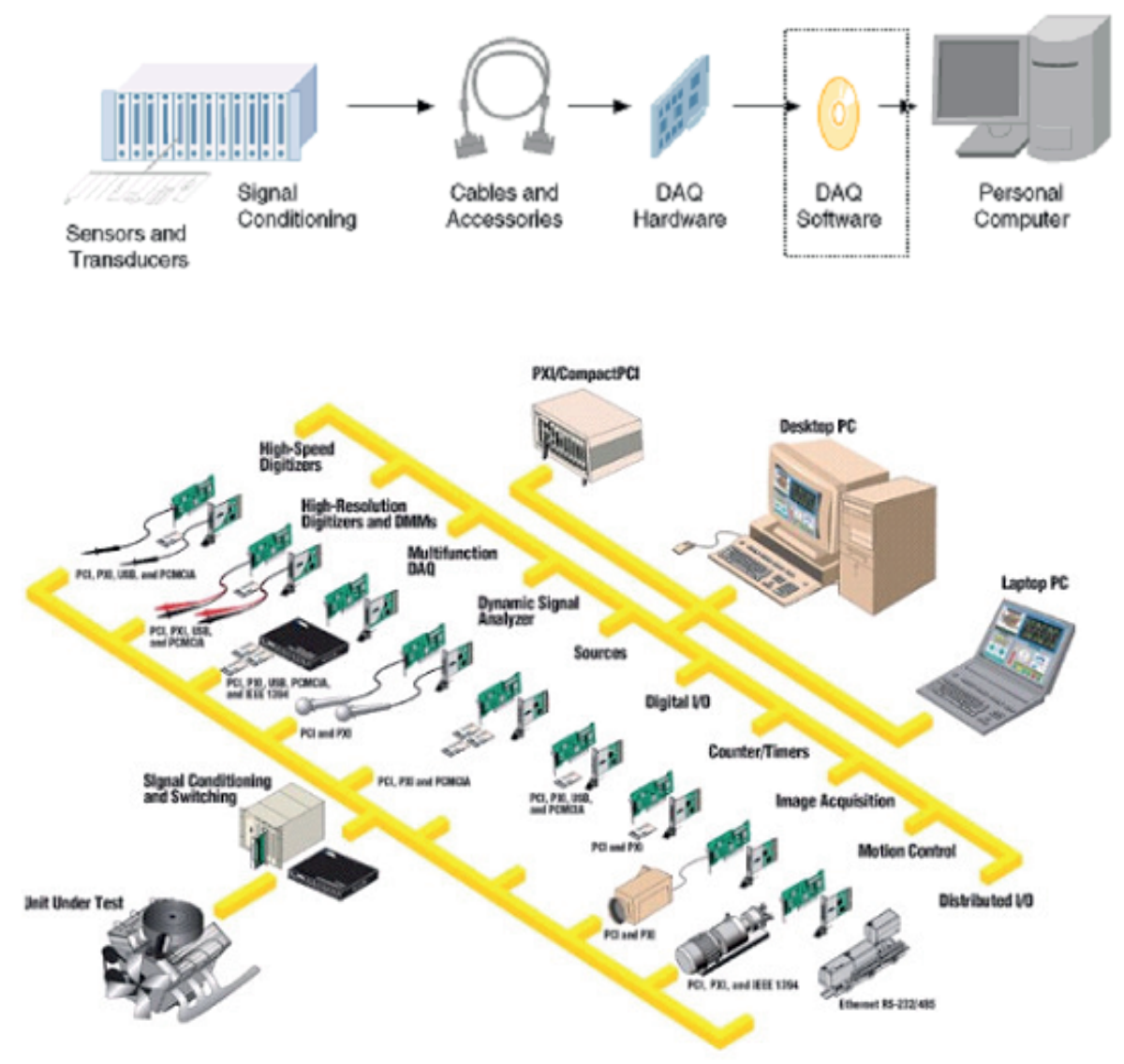

Fig. 1. Typical modules of a measurement and control system, which are the topics in BSc Curricula Measurement and Control Engineering at Faculty of Technical Sciences, University of Novi Sad.

\section{PROGRAMME STRUCTURE}

The outcomes of the learning process include knowledge, skills and competences which enable students to apply acquired knowledge to the problems arising in engineering practice, to use expert literature and to enable students to continue their studies, if they choose so. Students of this programme have obligatory and elective courses.

Elective courses are chosen from a list of suggested courses. An elective course can be replaced with one of the courses taught at the Faculty of Technical Sciences or the University of Novi Sad with the consent of the head of the study programme.

Courses are carried out in the form of lectures and practice. At lectures, while using the appropriate modern didactic-methodological methods, students become familiar with the course subject matter and are offered explanations that help them understand it more easily.
At practice classes, complementing the lectures, students solve specific engineering problems and are given examples which further illustrate the course matter. The practice classes can be auditory, computer or laboratory practice. Consultations also present an important segment of knowledge transfer.

A large number of laboratory practice in the professional subjects provides students to acquire practical knowledge needed to continue the career, as well as through joint work on the project and acquire the knowledge and skills that are not strictly professional, such as group work, project management, managing a group of people and so on. Number of the students per group depends on the character of practice.

Student obligations may comprise of research papers, homework assignments, as well as smaller professional project assignments. Every activity of the student during the teaching process is evaluated and graded in accordance with the rules established at the Faculty level. The number of obtained credits is represented by the unique methodology and it reflects student load. 


\section{PROGRAMME OBJECTIVES}

The goal of the study programme is to educate students for the profession of an engineer of electrical and computer engineering-Bachelor in accordance with the economy needs, knowledge based economy and society at large. The study programme Measurement and Control Engineering is designed to provide acquisition of competencies necessary for the graduated engineer of electrical and computer engineering.

An important role of all teachers in this study programme is to educate top engineers ready for active involvement in the regional development and responsible for the maintenance of the high-tech and research potential of Vojvodina and Serbia in the field of electrical and computer engineering. The objective of the study programme is fully in accordance with the main objectives and goals of the Faculty of Technical Sciences and is in line with the high educational standards proposed by our educational system.

Also, the realization of this study programme educates engineers of electrical and computer engineering who possess knowledge necessary for the labour market in Serbia, the region and beyond.

\section{PROGRAMME GOALS}

The objectives of the study programme can be classified in the following categories: Technical knowledge: Acquiring the necessary knowledge in the field of electrical and computer engineering combined with the knowledge of mathematics, physics and selected social studies.

The programme ensures the in-depth knowledge in measurement suystems, automatic control and power drives. Practical knowledge: The focus of this program is placed on practical knowledge in identifying technical issues, terms of project requirements and formulating a plan for the implementation and resolution of technical problems using skills and knowledge in various areas.

Engineers who complete their studies in this program of study will be competent in the design and development of complex measurement and regulation systems and their component parts, and will be trained for later master's and doctoral studies and monitoring of rapid technological development in the field of electrical engineering and computer science. Communicative skills and team work.
Acquiring the necessary knowledge and skill in at least one world language with the ability to present one's results to the professional and wider audience as well as developing the team work skills. Subjects in the field of project management will provide ability of critical thinking, understanding the importance of preparation, leadership roles in the team, and each participant for the timely completion of the project.

Preparation for further studies: One of the specific objectives of the study programme is the development of students' awareness of the necessity for permanent education and advancement in the field of electrical and computer engineering. Acquiring the necessary knowledge which will enable the continuation of student's education at graduate, specialization or doctoral level.

\section{GRADUATES' COMPETENCIES}

After completing the study programme, students will be competent for the development, engineering, design and application of modern complex systems and their parts in the field of electrical engineering, especially in measurement and control systems that include wide area from measurement of electrical and nonelectrical quantities, data processing, automation and control to control of power drives.

Electrical and computer engineers who have completed Computing and Control Engineering study programme have the competence to solve real life problems in practice as well as to continue education if they decide to do so. Their competences include, primarily, critical thinking, the ability to analyze a problem, synthesize a solution, predict the behaviour of the chosen solution with the clear idea of the advantages and disadvantages of the chosen solution.

Students who successfully complete the study programme in the field of measurement and control engineering will be able to:

- understand and apply fundamental knowledge in electrical engineering.

- apply knowledge in mathematics, physics and engineering disciplines.

- design systems, components and processes based on the provided specifications.

- use engineering approach and modern software tools in engineering practice.

- design and carry out engineering experiments and afterwards analyze and interpret obtained data.

- understand, notice, formulate and solve engineering problems. 
- advance their knowledge and follow technological development.

- work in a team composed of experts in different fields.

- understand professional and ethical responsibility of electrical and computer engineers.

- communicate efficiently.

- understand impact of engineering solutions on society and environment.

- accept the need and actively participate in life long education.

\section{CURRICULUM}

The curriculum of the undergraduate academic studies Measurement and Control Engineering is designed to satisfy objectives of the study programme. In the structure of the study programme there are academicgeneral education, theoretic-methodological, scientific-professional and professional-applicative courses. In order to meet individual preferences of students, study programme curriculum contains elective courses as well, through which student obtain particular competences within the elected modules. All courses last one semester and are worth certain number of ECTS credits, where one credit corresponds to approximately 30 hours of student activity.

The order of course lectures in the study programme is such that the knowledge required for the following courses is gained through previously attended courses. In order to successfully complete this study programme, students must collect at least 240 ECTS credits. Curriculum includes description of each course which contains the name of the course, the type of the course, the year and semester of the studies, the number of ECTS credits, the name of the lecturer, the course objective with the expected outcome, the knowledge and competences the student will acquire, the prerequisites for taking the course, the course content, the recommended literature, the methods of lecturing, the knowledge tests and evaluation and other relevant data.

Professional practice lasting 45 hours is an integral part of this curriculum and it is realized in adequate scientific-research institutions, innovative organizations, companies, public institutions, etc. Students complete their studies by writing the graduate thesis which consists of theoretical-methodological preparations necessary for complete understanding of the field, writing and defense of the graduate thesis.
To perform a study programme, the adequate human, spatial, technical and technological, library and other resources suitable to the study programme features and predicted students' number are to be provided. Lectures are held in amphitheatres, classroomas and specialized computer or measurement laboratories (between 12 and 20 work places) which are equipped with contemporary equipment where students experimentally prove and deepen the matter taught in lectures. Library is within the Faculty of Technical Sciences building, and has enough bibliographic units which are relevant for this study programme. All courses within the study programme are accompanied by adequate textbook literature, teaching aids and props available for normal teching process.

The quality control of the study programme is performed regularly and systematically through selfevaluation and external quality control. At the Faculty of Technical Sciences there is a perennial postitive practice of interviewing students through questionnaire. The quality control of the study programme is perfomed through following activities: (a) interviewing students by questionnaire at the end of the lectures for the given course, (b) interviewing graduated students by questionnaire about study programme quality and logistic support to the studies at the diploma awarding ceremony, (c) interviewing students by questionnaire about evaluation of logistic support to the studies at the certification of the study year, (d) interviewing students by questionnaire when enrolling to the year of study. Students assess study programme of the previously completed school year, (e) interviewing lecturing and non-lecturing staff by questionnaire about quality of the study programme and logistic support to the studies.

\section{ACKNOWLEDGMENT}

This work is partly supported by the ELEMEND project (project code: 585681-EEP-1-2017-EL-EPPKA2CBHE-JP).

\section{REFERENCES}

[1] Study programme accreditation material: Measurement and control engineering - Master Academic Studies, University of Novi Sad, Faculty of Technical Sciences, Novi Sad, 2012, http://www.ftn.uns. ac.rs/n1977852084/ (12.03.2018.) 